(Cvenisg

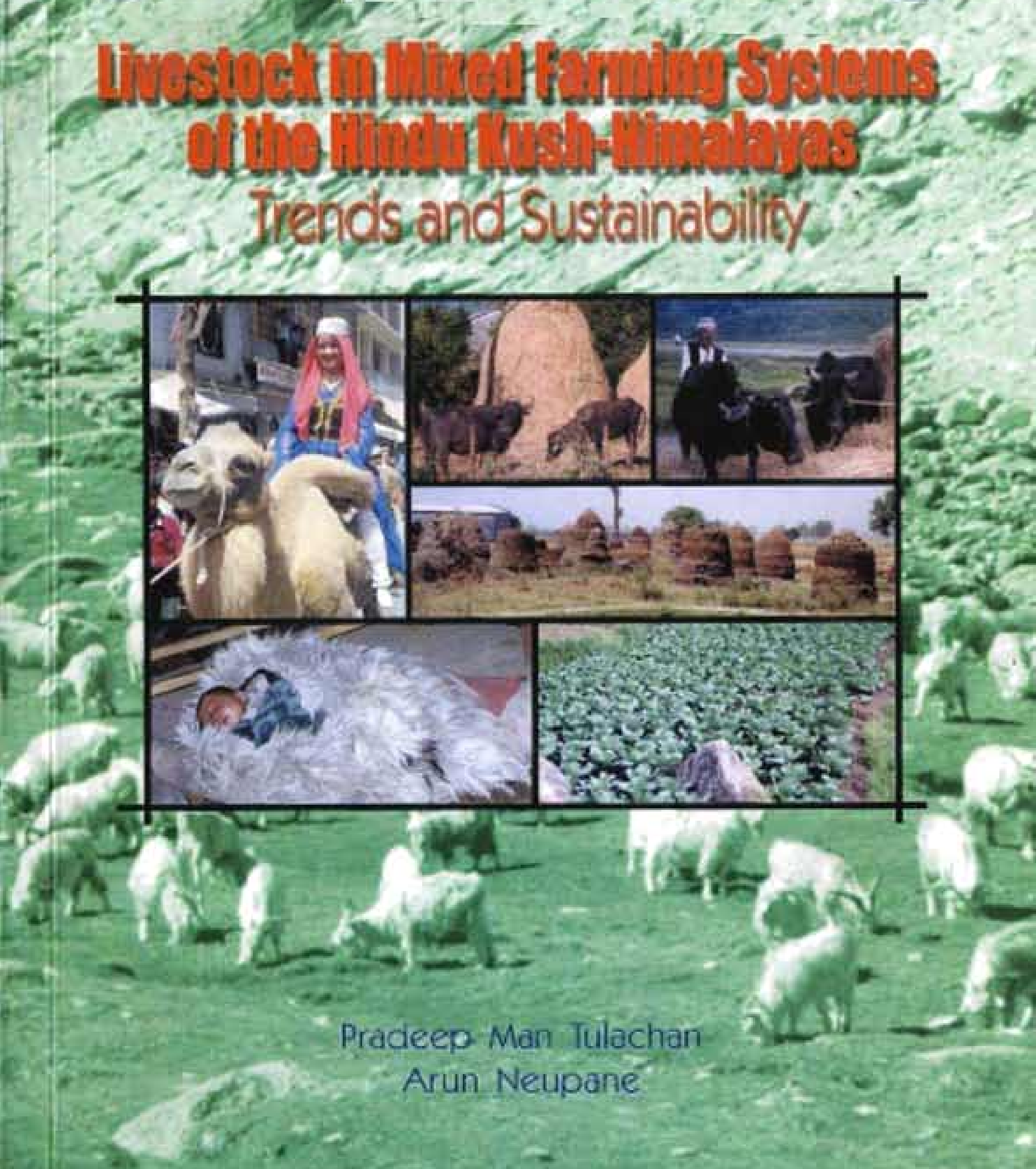

20

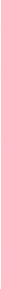




\section{Livestock in Mixed Farming Systems of the Hindu Kush-Himalayas Trends and Sustainability}

Pradeep Man Tulachan

Arun Neupane

Food and Agriculture Organization of the United Nations International Centre for Integrated Mountain Development 
Copyright () 1999

$\mathrm{FAO}$, Rome

International Centre for Integrated Mountain Development

All rights reserved

ISBN 9291150711

\section{Published by}

International Centre for Integrated Mountain Development

G.P.O. Box 3226,

Kathmandu, Nepal

\section{Editorial Team}

Greta Mary Rana (Senior Editor)

Rosemary Thapa (Consultant Editor)

Sushil Man Joshi (Technical Support and Layout)

Asha K. Thaku (Cartography and Design)

\section{Cover Plates}

Goats grazing on a high mountain pasture, Indian

Himalayas (Background) - Authors

Lady on a camel in a high mountain valley, Indian Himalayas - Authors

Baby sleeping in a fur rug, Indian Himalayas - Authors

Storage of FYM in the UP Hills, Indian Himalayas - Authors

Use of draught animals in the hills of Nepal - Authors

Feeding cattle and storage of paddy straw in the hills of Nepal - Authors

Cabbage field in the hills, Nepal - Authors

The views and interpretations in this paper are those of the author(s). They are not attributable to the FAO, Rome, or the International Centre for Integrated Mountain Development (ICIMOD) and do not imply the expression of any opinion concerning the legal status of any country, territory, city or area of its authorities, or concerning the delimitation of its frontiers or boundaries. 
This January, ICIMOD embarked on the Second Regional Collaborative Programme for the Sustainable Development of the Hindu Kush-Himalayas (RCP II) that covers the period from 1999 to 2002. During this period, ICIMOD will focus on three programme areas. First, poverty reduction and sustainable livelihoods; second, gender-balanced mountain development; third, sustainable management of the mountain commons.

Within RCP-II, emphasis will be on the overall improvement of the economic situation of marginal farms, which we define as farms that are either too small in size or too low in productivity to produce sufficient food and income for the farmers household. We will address the livestock sector in this context in two ways. First, generating knowledge on the present situation of the livestock sector in the $\mathrm{HKH}$; and second, through developing a better understanding of how livestock can fit into a mountain-specific niche as an income generating option for improving livelihoods.

Perhaps the role of livestock is understood best by those who farm the mixed crop-livestock systems in the Himalayas where the land is often steep and fragile. Land-use planners and policy-makers have tended to neglect this important component of the farming system, despite the fact that livestock contributes in many ways to the sustainable livelihood of mountain households.

For the last 10 to 20 years, considerable changes have been taking place in the livestock population structure and management systems in the mid-mountain areas of the Himalayas where mixed crop-livestock farming is the dominant agricultural system. Many studies have been carried out by different institutions and agencies; 
however, these were in different geographical locations and with different objectives related to livestock sector development in the $\mathrm{HKH}$ region. Knowledge about how these changes and transformations are affecting the sustainability of livestock production systems has not been brought together to help our understanding of the transitions that are taking place. Furthermore, the constraints and opportunities of sustainable livestock management have not been well documented. It is in this context that ICIMOD and FAO have jointly carried out a state-of-the-art review to fill the gaps in our understanding and to identify further priority areas for research.

I thank all of the participants who attended the one-day workshop on 'Mixed Crop-Livestock Farming Systems in High Pressure Areas of the Himalayan Region', held jointly by ICIMOD and FAO in February 1999, to draw on their knowledge and experience and thereby sharpen the focus and fill in the gaps in an earlier draft of this study. This activity is another example of the excellent institutional relationship between FAO and ICIMOD. This is a natural alliance, given our common mandate of poverty reduction and environmental conservation, particularly in rural areas. By linking FAO's global mandate, perspective, and specialised expertise; and ICIMOD's mountain focus, regional perspective, and multidisciplinary approach; we have already conducted many successful collaborative activities with different divisions of FAO. I am glad that the present study has now allowed us to establish excellent contacts with FAO's Animal Production and Health Division.

I am grateful to Mr. Juhani Maki Hokkonen, FAO-Rome, for sponsoring this study. I would like to thank my colleagues, Dr. Pradeep M. Tulachan and Arun Neupane, for undertaking this job and Dr. Mahesh Baskota and Dr. Tej Partap for providing support and advice. I hope that this state-of-the-art review will lead to better understanding of the critical issues affecting the livestock sector in the mixed crop-livestock farming areas and contribute to policies and programmes that will improve the livelihoods of farming households in the Hindu Kush-Himalayas.

\author{
Egbert Pelinck \\ Director General
}


The authors wish to thank Dr. Mahesh Baskota, Deputy Director General, ICIMOD, for his support and advice. The authors would also like to thank all the participants who contributed to the joint ICIMOD-FAO workshop on 'Sustainable Management of Livestock in Mixed Crop-Livestock Farming Systems of High Pressure Areas in the Himalayan Region' held at ICIMOD on 4 February, 1999, for their valuable inputs.

We would like to thank both Mr. Juhani Maki-Hokkenon and Dr. Hiroshi Kudo from FAO, Rome, for funding the study and for their valuable comments

We are also grateful to the International Livestock Research Institute (ILRI) for funding the Livestock Database Project from which some data have been taken for the present study.

Pradeep M. Tulachan

Arun Neupane 


\section{$\Delta \nabla$}

This is a state of the art review paper which analyses the changes taking place in livestock production management in mixed croplivestock farming systems. It focus on the area of the Hindu-Kush Himalayas that are under pressure. The paper describes the changes taking place in livestock population and composition in the hills and mountains of Nepal and in the Central and Western Indian Himalayas. It examines the increasing trend of smallholder dairy farming in mountain areas and discusses up various issues related to it. In light of the transition taking place in livestock production management, implications on soil fertility, demand for fodder, and changing linkages to the environment are assessed. Gender aspects in livestock management are also explored.

Livestock development policies of the past are reviewed and the necessity for renewed focus emphasised. In concluding, based on the changing patterns of livestock production systems and the lack of success of past development experiences, strategies for sustainable management of livestock production in mixed croplivestock farming systems of the Hindu-Kush Himalayas are outlined. 
ADB Asian Development Bank

APROSC Agricultural Projects' Services' Centre

CPR Common Property Resources

DDC National Dairy Development Corporation

FAO Food and Agriculture Organization

FYM Farmyard Manure

$\mathrm{HH} \quad$ Household

$\mathrm{HKH} \quad$ Hindu Kush-Himalayas

HP Himachal Pradesh

HYV High-yielding Variety

ICIMOD International Centre for Integrated Mountain Development

INGO International Non-government Association

LRMP Land Resources' Mapping Project

LSU Livestock Unit

MPA Milk Producer Association

N Nitrogen

NDDB National Dairy Development Board

NGO Non-government Association

NRB Natural Resource Base

TDN Total Digestible Nutrient

TOR Terms of Reference 
UP Uttar Pradesh

VDC Village Development Committee 
Preface

Acknowledgements

Abstract

Acronyms

Chapter 1: Introduction

The Context

Terms of Reference/Areas of Enquiry

Study Areas and Methodology

Chapter 2: Livestock Composition in the Himalayan Mountains

Introduction

Population Growth and Land Fragmentation

Trends in Livestock Population and Herd Composition

Land Fragmentation and Changes in Livestock

Composition

Chapter 3: The Increase in Smallholder Dairies in Mountain Areas

Importance of Livestock in the Farm Household Economy

Increasing Trend of Smallholder Dairy Farming

Smallholder Dairy Dynamics in the Middle Hills of Nepal

Development of Smallholder Dairies in the Indian

Himalayas 
Increase in Improved Animal Breeds

Relationship between the Distribution of Cross-bred

Cattle and Veterinary Services in HP

Implications on the Natural Resource Base and the Environment

\section{Chapter 4: Sustainable Management of Livestock,} Feed Resources and Soil Fertility

Inter- relationship between Livestock, Soil and Plants 33

Fertility Maintenance Measures 34

Soil Fertility Decline and Livestock Management Practices 36

Declining Sources of Fodder and Farmers' Responses $\quad 39$

Feed Resources from Private Land and Implications for CPRs

Perceptions of the Role of Community Forestry

Chapter 5: Gender and Livestock

Gender Division of Work

Gender Equity and Decision-making

Changing Gender Roles

Gender Roles in Soil Management

Chapter 6: Livestock Sector Development Experiences

Animal Breed Improvement

Animal Feed Improvement

Animal Health

Lessons from Livestock Sector Development and Past Policies

Framework for Livestock Sector Development in the Himalayas

\section{Chapter 7: Strategies for Sustainable Management of Livestock in Mixed-Crop Livestock Farming Systems}

Improvement in the Feed Resource Base 
Reassess the Price Policy for Milk $\quad 70$

Promotion of Manufactured Livestock Feed 71

Fostering Credit and Savings' Institutions / Minimisation of the Risk in Livestock Raising 73

Promotion of Appropriate Technologies for Inaccessible Areas

Promotion of Diversification through Value-adding to Increase Returns

Integration of Gender Concerns

78

Promotion of Micro-Livestock for Marginal and Disadvantaged Farmers

Improvement of Soil Fertility through Better Management of Livestock and Forage Crops

References

85

Annexes

93 